\title{
La Dialéctica trascendental o la sinrazón de la metafísica
}

\author{
Lourdes Flamarique \\ Universidad de Navarra
}

The author shows how Kant's trascendental philosophy only allows metaphysics when it is understood as dialectical. This dialectic metaphysics is not a "science" about being, but a "science" about reason and its interests.

Es ya un lugar común hablar de la disolución moderna de la metafísica que culmina en Kant, así como de la traslación del punto de mira de la inquietud humana por saber desde la realidad a la subjetividad.

La experiencia radical para el estudioso moderno -sea cual sea el ámbito de su saber- es él mismo como cognoscente. Su propia actividad no pasa inadvertida, no queda oculta, ni es transparente, sino que más bien hay que hacerla patente, completamente lúcida, sin la menor sombra, puesto que es la actividad $^{1}$ fundamental por la que entramos en contacto aunque sea a través de sensaciones y conceptos- con lo otro (llámese realidad, naturaleza, sociedad, Dios, etc.).

Por ello no es legítimo pretender haber fundado los principios, método, alcance de una disciplina cualquiera - no es legítimo, por tanto, hacer una antropología, una ética, una teoría social, una teodicea- ignorando la mediación cognoscitiva que

1 Si utilizo este termino para referirme a los actos de conocimiento, es porque considero que se acerca más a aquellos con los que Kant se refiere al conocer. 


\section{TOPICOS}

hace posible nuestro conocimiento de la realidad humana, moral, social, etc.; es decir, sin que toda disciplina dependa constitutivamente de una teorfa que dé cuenta de nuestro modo de conocer. Este será así el paso previo e indispensable para fiarse de la actividad como cognoscente; paso que, al mismo tiempo, muestra los límites y el alcance de la facultad cognoscitiva y la precariedad -pero, por ello, también la irrefutabilidad- de la noción de realidad de la que se dispone.

En una época de despliegue de la investigación cientifico-experimental basada en el cuidado de los procesos investigadores según un método previo, la gnoseología no es descriptiva, no se centra en las facultades, sino que se hace método ella misma; es método de método, es decir, de lo que ya de por sí tiene un carácter metódico: la gnoseología. La teorfa moderna del conocimiento trata de operaciones en tanto que éstas constituyen pasos de un proceso del que resulta la objetividad. En esos pasos, en su enlace, irán quedando incoados los principios a partir de los cuales se pueden explicar los distintos ámbitos del saber, así como las diferentes direcciones de la actividad del espíritu humano.

La metodologfa o teoría del conocimiento tamiza y calibra las cuestiones centrales del pensamiento moderno; esto ocurre de una manera eminente en la filosofía de Inmanuel Kant, quien, recogiendo sobre todo la tradición moderna, elimina las formulaciones anquilosadas $y$, con ello, inicia una nueva etapa.

Es bien conocido que las preocupaciones radicales de Kant son morales y religiosas -y por tanto, como buen ilustrado políticas-; sin embargo, también es sabido que tras el llamado perfodo precrítico en el que Kant esboza su visión de los temas caracteristicos de la filosofía racionalista -incoando una transformación de ellos que alcanzará su fuerza operativa en el perfodo crítico-, inaugura esa nueva etapa de su pensamiento con una gnoseología. En la Crítica de la razón pura desarrolla 
con detalle y prolijamente los principios del conocer y de la realidad conocida; algunas de esas cuestiones son clásicas en la filosofía, otras son acuñadas y definidas de un modo peculiar: el que resulta de una de las nociones claves en la teorfa kantiana del conocimiento, la unidad sintética del conocer. En la tradición racionalista encontramos la distinción entre juicios analíticos y sintéticos, -consecuencia de las dos operaciones más características de la razón: el análisis y la síntesis-, las expresiones a priori y a posteriori, nociones como naturaleza o experiencia regulada por leyes. Todos ellos reciben, sin embargo, una nueva significación en virtud de los términos propios de la filosofía trascendental: condición a priori de posibilidad, concepto sintético, esquema temporal, etc. Los viejos conceptos reciben una nueva significación; hacerse con ellos, con su sentido, equivale a comprender la propuesta crítica.

La Crítica de la razón pura 0 análisis y fundamentación del conocimiento humano abordará ese conocimiento que no queda revalidado desde un punto de vista meramente pragmático, sino que queda formulado y justificado mediante leyes y conceptos. Se trata de ese conocimiento universalmente compartido o compartible; de un conocimiento que pretende ser verdadero en todo caso y tiempo, es decir, necesario. Un conocimiento, por tanto, que se sitúa por encima del aquí y ahora de la realidad experiencial y del aqui $y$ ahora de la subjetividad cognoscente. Sólo este tipo de conocimiento plantea dificultades a primera vista - por no tener la evidencia de la intuición empirica - y, sin embargo, solo este conocimiento permite tener una noción unitaria y universalmente válida de la realidad conocida; coloca asi al hombre en situación de ventaja sobre la realidad, puede prescindir de la presencia fáctica del objeto de conocimiento gracias a los conceptos; es la ventaja que la modernidad empieza a conocer bajo el nombre de técnica. 


\section{TOPICOS}

El conocimiento que en el siglo XVIII lleva consigo de modo indiscutible esas notas de necesidad y universalidad es la ciencia (física, matemática, astronomía, etc.). Por ello, hay quien ha interpretado la Crítica como una teorfa de la ciencia.

Y, sin embargo, en esta obra Kant se servirá de la ciencia y de su método para extraer de ellos los elementos de los que dimana la necesidad y universalidad, pudiendo mostrar mediante el análisis - en qué consiste el uso de las facultades cognoscitivas en su ejercicio y acoplamiento más efectivo, por unificado y necesario.

En la Introducción a la Crítica, Kant va tras la pista de la necesidad y universalidad de una actividad cognoscitiva que siempre avanza en la investigación de la realidad; por tanto, de un conocer que no es mero análisis, pero que puede ser considerado tan cierto y seguro como éste.

En su carácter empírico (presencial) la realidad es conocida por nosotros particularmente, con la certeza de lo que vemos u of́mos ahora - tal vez antes no lo percibimos y después tampoco lo percibiremos-; sometidos a la fugacidad del puro instante, podemos afirmar con necesidad que sentimos, cuando sentimos, pero nada más podemos decir sensiblemente de la realidad en el caso de que no sintamos nada. A partir de esto no podrfamos formular una ley.

La fuente de la necesidad y universalidad de nuestro conocimiento de la experiencia, de la realidad sensiblemente percibida, debe ser independiente de la simple sensacion, debe ser a priori. Kant recoge formas a priori, condiciones que hacen posible el conocimiento unificador de la realidad tanto en el nivel de la sensibilidad, como de la imaginación $y$, fundamentalmente, en el del entendimiento.

La objetividad conocida es objetividad, es decir, unidad de datos formulable universalmente, ligada y enlazada en todos sus elementos, en virtud de la acción sintética de las categorías 
(por parte del entendimiento), de los esquemas trascendentales (por parte de la imaginación) y de las formas a priori de la sensibilidad: espacio y tiempo.

Kant no pretende decir que lo que vemos, oímos, etc, que lo que captamos de la realidad -el mundo que nombramos y compartimos- sea a priori; ni tan siquiera que sea invención de nuestra subjetividad. Quiere decir algo mucho más interesante y más diff́cil de rebatir: que la experiencia del mundo revela lo que somos y cómo somos, es decir, cómo podemos conocer. Es el cómo lo que importa, no el qué (aunque claro está, al qué no le es igual cualquier cómo).

Cuando el hombre moderno designa la realidad con el término naturaleza, está reconociendo en ella un reino regido por leyes, por categorfas universales en las que expresa lo que es ahora y siempre. Kant pretende haber mostrado en la Analítica Trascendental no sólo cómo es posible este conocimiento para la razón humana, sino además que éste es el único uso de la facultad cognoscitiva que proporciona una noción unitaria de la realidad, por tanto un conocimiento de ésta que permite aplicar el viejo lema saber para poder. El principio o ley general de la realidad como naturaleza es el principio de causalidad mecánica; y constituye el paradigma de la explicación total de un fenómeno. Conocer según necesidad y universalidad, significa explicar cómo se origina un fenómeno, es decir, señalar su causa en el mismo orden de fenómenos.

La objetividad conocida según condiciones de posibilidad a priori, la naturaleza (experiencia en tanto que sometida a leyes) es simplemente eso: el objeto de conocimiento conformado por las distintas formas a priori de los niveles facultativos de la subjetividad humana. La realidad no se refleja en nuestros sentidos e inteligencia como en un espejo, sino que la información material o realidad sentida es percibida por el 
sujeto, ordenada y enlazada por las formas espacio-temporales y por las categorías.

La realidad de la que podemos hablar es experiencia sentida, percibida y conceptualizada: estos términos designan el referente de nuestro conocer como fenómeno. No conocemos la realidad en sí misma (noúmeno), sino que conocer significa sentir, percibir, enlazar según conceptos; por consiguiente, 10 experimentado es ya experimentado - sentido, percibido, etc.cuando tenemos noticia de él.

\section{El método crítico}

Las obras críticas tienen una estructura, una arquitectónica propia, en la que cada paso es un momento necesario del proceso argumentativo.

Por ello en la Crítica de la razón pura, en la que se da cuenta de nuestro conocer - del legítimo, que se expresa en leyes, y del ilegítimo, incapaz de proporcionar una unidad y sometido, por ello, a oscilaciones y discusiones-, también se da cuenta de la realidad e irrealidad, de la fiabilidad de nuestras espectativas ante lo que nos circunda y ante lo que somos. Asi los errores de la razón son falsos puntos de apoyo de nuestra concepción del mundo que no nos permiten disponer acertadamente de las cosas; las ilusiones de la razón son idealidades que en el ámbito cultural, en la mentalidad de una época se han confundido con 10. real o lo han suplantado.

Si verdaderamente la crítica a la razón está bien hecha, podrá dar cuenta de todo el saber pasado y presente acerca del mundo y del hombre, y, en esa medida, establecer el saber definitivo acerca de la realidad; es decir, podrá proporcionar la verdadera estructura de lo que llamamos mundo o realidad.

Por eso la argumentación de la Crítica construye y desmonta según un orden y una coherencia que la propia 
reflexión trascendental hace posible: los temas y cuestiones no aparecen de cualquier modo, sino que la reflexión crítica es quien los sitúa aquí 0 allá. La artificiosidad de la localización de los temas no es un síntoma de arbitrariedad, sino del predominio de lo ideal sobre lo real.

Casi al final de la Analítica ${ }^{2}$, Kant apunta el escaso alcance de los principios legítimos del conocimiento de la experiencia frente a las posibilidades ilimitadas de una razón guiada por principios erróneos. El error que hay que evitar, obedece a principios también racionales. Su fuente está en la entraña de la razón, no depende del ejercicio empírico de las facultades (por tanto de condiciones más o menos sensibles según Kant).

La Crítica revela los principios de la razón y su alcance; unos son del conocer, otros del pensar. Si la primera parte de la obra muestra el edificio de las condiciones a priori de la posibilidad de la experiencia, también habrá una arquitectónica para los objetos del pensar, la que sus principios hacen posible; incluso pese a que no tengan validez alguna en orden a los fenómenos de cualquier experiencia posible. La arquitectónica del conocimiento no se funda en el orden real, sino racional.

La Dialéctica trascendental es el modo arquitectónico de dar cuenta de los errores de una razón que explora esas posibilidades más allá de los principios del conocimiento empírico y que, sin embargo, no siendo consciente de su naturaleza, pretende haber logrado un saber sobre la realidad. La metafísica es la disciplina más controvertida; en la filosofía trascendental se explica por qué es así.

Cuando en 1966 Heimsoeth publica sus comentartos a la Dialéctica trascendental de la Critica de la razón pura señala la ausencia de un comentario semejante en el marco de los estudios

${ }^{2}$ Kr r V, A 235, B 294. 


\section{TOPICOS}

kantianos y su conveniencia, al tiempo que menciona ${ }^{3}$ los trabajos de Vaihinger ${ }^{4}$, Kemp Smith5 y de Paton ${ }^{6}$; sin embargo, estos autores no van en su análisis más allá de la Estética Trascendental.

Efectivamente la Dialéctica apenas ha sido comentada y cuando se entra en ella, se hace como si sólo importara el tratamiento que reciben determinadas cuestiones y no ella misma como una parte imprescindible de la Crítica. Respecto a la mayoria de los actuales comentadores de Kant se puede decir lo mismo: se sigue sistemáticamente la exposición de la Analítica, mientras que los temas y argumentos de la Dialéctica apenas quedan enmarcados metodológicamente y son oscurecidos desde la universalidad y necesidad alcanzadas para la objetividad empírica.

La Dialéctica es una pieza compacta -su extensión y densidad produce, a veces, esa impresión al lector- que, en interna conexión con la Analítica, trata - según principios- de los intereses últimos de la razón; intereses que -como ya señalaba antes- están íntimamente ligados a los que desarrolla la primera parte de la Crítica; por ello, no son ajenos a la metodología crítica, y constituyen un corpus temático inseparable de la exposición de los principios del conocimiento empírico.

${ }^{3}$ HeIMSOETH, H.: Transzendentale Dialektik, I. Walter de Gruyter, Berlín, 1966 , VII.

4 VaiHINGer, H.: Kommentar zu Kants Kritik der reinen Vernunft. Schmidt, Stuttgart, $2^{2}$ ed., 1922.

5 Kemp SMith, N.: A Commentary to Kant's 'Critique of Pure Reason'. Macmilan and Co., Londres, 2: ed., 1923.

${ }^{6}$ Paton, H. J.: Kant's Metaphysic of Experlence: A Commentary on the First Half of the Kritik der reinen Vernunft. Allen \& Unwin, Londres, 1936. 
Como señala Heimsoeth en la obra mencionada, "para Kant mismo esta segunda parte -la que tiene el título acuñado por él Dialéctica Trascendental- era de hecho el verdadero objetivo de la obra (...); la crítica de lo dialéctico en toda metafísica futura debía proporcionar el soporte para la propia reconstrucción de ésta"7. De ahí la relevancia de los temas que en ella comparecen y el rigor pretendido en su exposición. En el Prólogo a la segunda edición de la Crítica se anuncia dónde y por que la metafísica tradicional fracasa: con la deducción de nuestra capacidad de conocer a priori, sabemos que jamás podemos traspasar la frontera de la experiencia posible, lo cual constituye la tarea más esencial de esa ciencia ${ }^{8}$. La metafísica futura deberá abordar también esa tarea. El tratado del método así define Kant la Crítica de la razón pura- indicará cómo es posible ésta. "Siempre ha habido y seguirá habiendo alguna metafisica, pero con ella se encontrará también una dialéctica de la razón pura que le es natural. El primero y más importante asunto de la filosofía consiste, pues, en cortar, de una vez por todas, el perjudicial influjo de la metafisica taponando la fuente de errores' 9 . La Dialéctica completa este objetivo al que también mira la Analítica.

La Dialéctica es sobre todo la lógica de la ilusión ${ }^{10}$. Kant distingue la ilusión de lo que es simplemente probable (aquello de lo que se conocen razones insuficientes; el conocimiento es, por tanto, defectuoso, pero no falaz); también señala que el

\footnotetext{
${ }^{7}$ HeIMSOETH, H.: Traszendentale Dialektik, I, VIII.

${ }^{8}$ Cfr. Kr r V, B XIX.

${ }^{9} \mathrm{Kr}$ r V, B XXXI.

${ }^{10} \mathrm{Kr}$ r V, A 293, B 349 y ss. Lo ilusorio tiene un lugar destacado en la teoria kantiana del conocimiento, porque la instancia desde la que se legitima la crítica no es el yo-pienso o autoconciencia, sino la razón como naturaleza, cuyo destino - no alcanzado todavía - lleva a entender el error como un momento inevitable del vagabundeo de la razón.
} 


\section{TOPICOS}

fenómeno y la ilusión no son idénticos, es más en lo fenómenico -en cuanto tal- no hay posibilidad de verdad o de ilusión. Ni la verdad ni la ilusión se hallan en el objeto en cuanto intuido, sino en el juicio sobre éste en cuanto pensado. Es pues correcto decir que los sentidos no se equivocan, pero no porque juzguen correctamente, sino porque no juzgan en absoluto. Esto quiere decir que la verdad y el error se dan en el juicio; también la ilusión en cuanto conducente al error "sólo puede hallarse en el juicio, es decir, en la relación del objeto con nuestro entendimiento"11.

Se da el error donde confluyen elementos de diversa indole, donde hay operaciones distintas en relación a un mismo objeto; ası́ Kant señala que en un conocimiento enteramente concordante con las leyes del entendimiento -es decir, conceptual y no sensible- no hay error, como es sabido tampoco habrá verdad, pues sólo en un uso empírico estas leyes conducen a la verdad sobre sus objetos. Unicamente se dará una verdad formal, la que resulta de la concordancia con tales leyes. De igual manera, una representación sensible - una sensaciónno puede contener error, pues ni tan siquiera hay juicio en ella. "Ninguna potencia de la naturaleza puede, por sí sola, apartarse de sus propias leyes. Por tanto ni el entendimiento por sí solo (sin influjo de otra causa), ni los sentidos por sí mismos, se equivocan "12. El error es producido por un influjo inadvertido de la sensibilidad sobre el entendimiento. Este influjo consiste en fundir los motivos subjetivos del juicio con los objetivos, "haciendo que estos se aparten de su determinación"13.

\footnotetext{
11 lbidem.

12 Kr r V, A 294, B 350.

${ }^{13} \mathrm{Kr}$ r V, A 294, B 351. Kant añade en una nota a pie de página: "La sensibilidad, subordinada al entendimiento como objeto al cual aplica aquél su función, constituye la fuente de conocimientos reales. Pero en la medida
} 


\section{LA DIALECTICA TRASCENDENTAL O LA SINRAZON}

Ahora bien, la ilusión empírica se detecta con cierta facilidad; ésta -como veramos- se produce con el uso empírico de las reglas del entendimiento; sin embargo, la misma experiencia nos ayuda a salir de ella. De otra indole es la ilusion que conduce a un error tal que puede afectar al orden gnoseológico. Esta ilusión merece un análisis detallado, pues no se tratará en ese caso del error sobre una cosa determinada, sino sobre la objetividad en general. Esa ilusión es trascendental, y recibe tal calificativo porque afecta a principios que descubre la reflexión trascendental, a principios a priori; es decir, a aquellos que hacen posibles los objetos de conocimiento. Los lleva más allá de su uso legítimo y crea el espejismo de una ampliación del entendimiento puro ${ }^{14}$. Se trata del espejismo de una ampliación puesto que la explicación del error o de lo ilusorio es también operativa; es decir, no consiste en contenidos errados, afirmaciones equivocadas, sino - como en la Analítica- en usos, operaciones de la facultad superior. Ya se ha señalado que los temas o ámbitos de investigación nacen de las operaciones, dependen de ellas. Por eso cualquier ampliación del entendimiento puro es más la constitución de un campo de objetos por medio de la operación que el estudio o descubrimiento de una dimension de la realidad.

Volviendo al punto de partida, hay que decir que si el conocimiento verdadero se identifica con el ejercicio legítimo de la facultad, la ilusión o el error se identificarán con el uso o

en que ella influye sobre el acto mismo del entendimiento y en que lo determina a juzgar, constituye también el fundamento del error".

14 "Nos ocupamos sólo de la ilusión trascendental, que influye en principios cuyo uso ni siquiera se basa en la experiencia, caso en el que tendríamos al menos una piedra de toque para controlar si es correcto, sino que nos lleva, contra todas las advertencias de la crítica, más alla del uso empirico de las categorias y nos entretiene con el espejismo de una ampliación del entendimiento puro." Kr r V, A 295, B 351. 
TOPICOS

ejercicio ilegítimo, con las operaciones que transgredan la naturaleza de la razón.

"Llamaremos inmanentes a los principios cuya aplicación se circunscribe totalmente a los límites de la experiencia posible. Denominaremos trascendentes a los principios que sobrepasen esos límites"15. Kant distingue a estos últimos del uso trascendental o abuso de las categorias que se da cuando no se refrena al juicio con la crítica o no se atiende suficientemente a los límites del entendimiento. Son principios trascendentes "aquellos que nos incitan a derribar todos los postes fronterizos y a adjudicarnos un territorio nuevo que no admite demarcación alguna"16. Trascendental no es lo mismo que trascendente. Por tanto, los principios a priori de la Analítica son inmanentes, ya que solo deben aplicarse empíricamente -no trascendentalmente, sobrepasando los límites de la experiencia-; se oponen por tanto a los principios trascendentes que eliminan tales límites - dice Kant- o incluso ordenan traspasarlos ${ }^{17}$. La crítica debe ser capaz de detectar estos presuntos principios; y, además, detectarlos en su génesis

$15 \mathrm{Kr}$ r V, A 296, B 352. En este texto Kant se refiere a los principios del conocer que la Analítica de los principios ha fundado como criterios de verdad, según el uso justificado en la Deducción trascendental. Heimsoeth señala la diferencia entre los dos términos con los que Kant se refiere a los límites de la experiencia: Schranke y Grenze. "Los términos "Schranke" y "Grenze" se distinguen en Kant de tal modo que la fijación según principios de los límites de nuestro conocimiento es posible incluso como un poder determinar que abarca también la zona donde necesariamente la intención de una mirada comprensiva choca con sus limites irrebasables". Transzendentale Dialektik, I, p. 10.

${ }^{16} \mathrm{Kr}$ r V, A 296, B 352. La demarcación la realizan siempre los principios a priori, como también señala Kant en la Introdución a la Crítica del Juicio. Cfr. Gesammelte Schriften, V. Akademie Ausgabe. W. de Gruyter, Berlín, 1913, p. 174.

${ }^{17}$ Cfr. Kr r V, A 296, B 352-3. 
porque ahí se encuentra la clave de su alcance y validez. Kant mantiene también en la Dialéctica el status de la reflexión trascendental.

De este modo la ilusión trascendental - tal como Kant la concibe - forma parte esencial de la actividad de la razón; por ello, cuando la distingue de la ilusión lógica, señala que ésta desaparece tan pronto como la atención se concentra sobre el razonamiento. La ilusión lógica es la simple imitación de la forma de la razón sin atender a la regla lógica. "La ilusión trascendental no cesa, aunque haya sido descubierta ya y se haya comprendido su nulidad a través de la crítica trascendental. (...) La razón de esto se halla en que hay en nuestra razón (considerada subjetivamente como una facultad cognoscitiva del hombre) reglas básicas y máximas para aplicarla que tienen todo el aspecto de principios objetivos" 18 . Es por tanto, una ilusión inevitable -dice Kant - , $\tan$ inevitable como que el mar parezca más alto hacia el medio que en la orilla.

No es la primera vez que frente al error Kant responde con esa característica: es inevitable. El necesitarismo kantiano procede del restricto sentido de la verdadera fundamentación que hereda del racionalismo moderno y que pervive en el idealismo alemán posterior. La verdad como necesidad de lo que es así y no puede ser de otra manera quiere decir a priori. Kant es capaz de darle a este término - por otra parte, común en la filosofía moderna- la significación que permite lograr esa identidad entre la operación y los contenidos cognoscitivos que es máxima garantía de verdad: absolutamente independiente de toda experiencia en cuanto a su validez ${ }^{19}$. Lo a priori es indicio de

${ }^{18} \mathrm{Kr}$ r V, A 297, B 353.

19 Cfr. Kr r V, B 3. Vease también Flamarique, L.: Necesidad y conocimiento. Fundamentos de la teoría crítica de I. Kant. EUNSA, 


\section{TOPICOS}

máxima racionalidad $y$, consiguientemente, al desvelarse la actividad de la razón y sus principios, no cabe esperar una conexión a posteriori -por tanto, arbitraria-, sino que debe haber alguna necesidad, puesto que se trata de la razón a la luz de sí misma (no hay que olvidar que la ilusión es trascendental). La crítica no es casual, ni se hace de cualquier manera; revela principios necesarios a partir de una inevitabilidad que es el contrapunto subjetivo de la necesidad de lo a priori propio de la razón pura. La necesidad subjetiva del despliegue de lo racional -por tanto, también de lo dialéctico- queda iluminada por la necesidad objetiva de la naturaleza, cuya condición de posibilidad es una razón como autoconciencia. Naturaleza e historia de las ideas se hacen uno en la Crítica de la razón pura, al explicarse mutuamente gracias a la madurez de una razón que ha llegado a la autoconciencia20.

La Dialéctica se conforma con detectar la ilusión de los juicios trascendentes - añade Kant- y evitar que nos engañe. "Nunca podrá lograr que desaparezca incluso (como la ilusión lógica) y deje de ser ilusión. En efecto, nos las habemos con una ilusión natural e inevitable que se apoya, a su vez, en principios subjetivos haciéndolos pasar por objetivos'21. Si la ilusión es

Pamplona, 1991, (capitulo primero titulado Condición de pensabilidad o condición de posibilidad).

${ }^{20}$ En el primer prólogo a la Crítica de la razón pura y en los dos últimos capítulos de la misma (La arquitectónica de la razón pura e Historia de la razón pura) habla Kant de la naturaleza de la razón y de su despliegue. Esto lo he analizado en "¿Filosofia trascendental o hermeneútica de la razón vital?", Cuadernos Salmantinos de Filosofía, XVIII (1991), pp. 153-163.

${ }^{21} \mathrm{Kr}$ r V, A 297-8, B 354. Como señala también Heimsoeth, la ilusión es natural "no simplemente en el sentido de contrapuesta a una ilusión formada 'antificialmente', (...) sino también en el sentido de que tiene su fundamento en la 'naturaleza' (essentia) de nuestra razón (...). Siempre existio la ilusión y siempre permanecerá, incluso despues de lograda la ilustración y la introspección completa".Transzendentale Dialektik, 1, p. 5. 
natural e inevitable, también la dialéctica lo es; además se trata de una dialéctica que no tiene nada que ver con la ignorancia o la torpeza, sino que está anclada, que inhiere de forma inevitable en la razón humana.

Justamente porque la ilusión no se dice de contenidos ilusorios, sino de operaciones ilegítimas no basta con señalarlas para que desaparezcan. Un conocimiento falso se refuta y desaparece ante el conocimiento verdadero, pero no pasa lo mismo con una operación equivocada. Para entender esto-que el error que persigue la Crítica tenga que ver con la actividad cognoscitiva y no con doctrinas- hay que tener presente que los sistemas filos6ficos erróneos son tales por obedecer a principios que no son los naturales de la razón. Estos principios, es decir, estos modos de conocer - aun descubierta su falta de legitimidad- son posibilidades siempre presentes en la razón humana; pues la razón no está inmediatamente abocada a su plenitud. "La dialéctica tiene ante sí la tarea de desenmascarar en todos los campos de la metafísica el abuso de los principios tal como se produce en las tesis y argumentaciones de la razón pura $^{\prime 22}$.

\section{2. ¿Es toda metafísica dialéctica?}

En la Introdución a la Crítica se anuncia ya la perspectiva desde la que interesan los temas fundamentales de la metafísica. Pues, es precisamente en estos conocimientos "que traspasan el mundo de los sentidos y en los que la experiencia no puede proporcionar ni guía ni rectificación, donde la razón desarrolla aquellas investigaciones que, por su importancia, consideramos como más sobresalientes y de finalidad más relevante que todo cuanto puede aprender el entendimiento en el

22 HeIMSOETH, H.: Transzendentale Dialektik, I, p. 14-15. 


\section{TOPICOS}

campo fenómenico ${ }^{\prime 23}$. Kant parece despreciar ese conocimiento de lo inmediato, o de lo que dado en conexión causal con lo inmediato, no deja de ser siempre un saber sobre apariencias. Un conocimiento constitutivamente limitado, que permite avances notables en la explicación de los fenómenos, no colma las ansias de saber de una razón finita, al menos en un campo: el de la experiencia posible.

¿Puede la razón recorrer otros caminos del saber, en los que no se vea vinculada inexorablemente a algo que no puede controlar -es decir, realizar- de modo completamente autónomo? En palabras de Kant: "¿Podemos aislar a la razón? ¿Sigue siendo ésta, una vez aislada, una fuente específica de conceptos y juicios que surgen exclusivamente de ella y por medio de los cuales se refiere a los objetos?'24. La cuestion es, entonces, si cabe esperar que la razón pura disponga de principios propios para una metafísica entendida como ciencia de la realidad. Si la razón es soberana y, por tanto, capaz de legislar sobre esos grandes temas, entonces no es una facultad subalterna que establece nuevas conexiones con un material ya dado. Ahora bien, aunque la diversidad de las reglas y la unidad de principios sea una exigencia de la razón por la que tiende a lograr una total concordancia del entendimiento consigo mismo, este principio de unidad "ni impone una ley a los objetos, ni contiene el fundamento de posibilidad de conocerlos y determinarlos en cuanto tales. No es más que una ley subjetiva'25. Esas investigaciones más sobresalientes y de finalidad más relevante - de las que hablaba Kant-, lo son solo como exigencia.

En consecuencia, la Dialéctica no va a abordar los temas de esas investigaciones, puesto que quedan reducidas a una mera

\footnotetext{
23 Kr r V, A 3, B 6-7. El subrayado es mío.

24 Kr r V, A 305, B 362.

$25 \mathrm{Kr} r \mathrm{~V}, \mathrm{~A} 306, \mathrm{~B} 362$.
} 
exigencia de la razón, una inclinación inevitable; será ésta lo que la crítica debe iluminar. Aunque la razón pura trate de encontrar lo incondicionado del conocimiento condicionado, es decir, aquello con lo que la unidad de éste queda completa, la Dialéctica trascendental no se preguntará por la indole de la unidad lograda en cada una de la síntesis realizadas. Nuestro quehacer-dice Kant- es "examinar si el principio según el cual la serie de las condiciones (...) se extiende hasta lo incondicionado es o no objetivamente correcto; averiguar qué consecuencias se derivan de ello con respecto al uso empírico del entendimiento"26; es decir, lo que queda por hacer, una vez señalado que partimos de una ilusión, es mostrar si existe un principio ast con validez objetiva, averiguar si la necesidad o exigencia de la razón ha sido tomada por un principio determinante de un ámbito de la realidad.

¿Ha ganado algo Kant reduciendo las cuestiones sobre el alma (en definitiva sobre el carácter supranatural del hombre), el mundo y Dios a una mera exigencia natural de la razon? Son conocimientos que están llenos de consecuencias para el ser del hombre y su imagen del mundo. Justamente esto parece pensar Kant y, por lo mismo, considera que no pueden ser dependientes de ninguna experiencia, ni siquiera de la determinada a priori. En lo simplemente aparente no puede comparecer algo cuyo ser no se reduce a la facticidad. No se puede identificar el ser del hombre con las imágenes de las que él es origen; no se puede pretender encontrar como representación -es decir, condicionadamente-, lo que tiene carácter de incondicionado, la subjetividad (condición y condicionado no son intercambiables). Si el conocimiento es representativo, entonces no cabe confundir los objetos con lo que es en sí y por sí mismo. El

${ }^{26} \mathrm{Kr}$ r V, A 308-9, B 365. Es interesante la comparación que hace Heimsoeth entre este principio y el principium rationis sufficientis de la metafisica racionalista. Cfr. Transzendentale Dialektlk, I, p. 24-25. 


\section{TOPICOS}

representacionismo supone también que la relación entre realidad y conocimiento acabe siendo superflua, por lo que queda asegurada la irreductibilidad de la misma. Hubiera sido un gran error ligar a lo fenoménico la noción de mundo, la de su creador o la del ser del hombre, es decir, llegar a ellas por necesidades gnoseologicas o metodologicas (como en el racionalismo), cuando son las nociones en las que no cabe confusión de niveles: o son realidades en sí mismas o carecen de interés completamente. Su lugar propio no es la gnoseología. No pueden ser afirmadas como supuestos de toda experiencia, pues se puede conocer ésta según la verdad sin acudir a ellas, piensa Kant.

La filosofía que toma como punto de partida el conocimiento de la realidad qua conocimiento, impide con ello que en la primera aproximación a las cosas comparezcan diferenciados - para un análisis metafísico- los tres frentes de todo pensar: la realidad, la causa de la realidad y el ser que la conoce en tanto que cognoscente (este aspecto es anterior al de su libertad e inmortalidad).

La narración kantiana sobre el origen de estos conceptos está completamente encarrilada por la fijación del horizonte filosofico en lo gnoseológico ( $y$ es de sobra conocido que en estos casos lo gnoseológico deviene constitutivo o lógicoontologico).

A este planteamiento lógico-ontologico cabe puntualizar que efectivamente no conocemos las esencias reales de las cosas; es verdad que nuestra noticia de las cosas es fenómenica; y, sin embargo, no es verdad que ese carácter apariencial, fenómenico de nuestros datos sea el único material sobre el que construir con seguridad una ciencia de la experiencia. La connotación de apariencial, fenoménico que damos a ese conocimiento indica la capacidad de la facultad de diferenciar desde el principio lo gnoseologico y lo ontológico; por ello cabe reconocer como 
apariencia una noticia de algo y, por encima de la particularidad de lo fenoménico, aspirar a conocer la unidad entitativa - no meramente espacial o funcional- de las cosas. Por tanto, no estamos abocados irremisiblemente a una postura idealista. En esta misma línea, es preciso señalar que el auténtico empirismo se desmarca del representacionismo.

Tiene razón Kant cuando afirma que la razón humana no puede identificarse con lo meramente apariencial, porque en ese caso, no podría designarlo como tal (por ello, la Crítica no está completa sin abordar el uso puro de la razón); pero, lo que no tiene sentido es su pretensión de que el saber sobre lo apariencial sea de segunda instancia, es decir, reflexivo, cuando éste entra en juego en el mismo instante de la percepción (síntesis de la aprehensión en la intuición, dirfa Kant). Por ello, no es legítima la propuesta kantiana de que la metafísica o saber de lo no apariencial esté desligada de esa primera noticia de la realidad, porque en ella está su fundamento, la fuente de sus objetos. Kant considera que la razón humana es capaz de reconocer sus límites, pero sólo en segunda instancia; gracias a la reflexión crítica. Con ello, los temas de la metafísica son competencia exclusiva de una razón pura, puesto que la objetividad empírica quedo suficientemente constituida en la vinculación de lo $a$ priori al dato sensible.

Kant señala cómo los temas de la metafísica son inevitables, porque son la otra cara de la objetividad. Si ésta responde a condiciones a priori, tambien lo que queda diferenciado de ella responderá a principios racionales, pues en el mismo constituirse la objetividad aparece su limitación. Los dos elementos de la diferencia son tratados temáticamente y según sus principios, pero la razón no aborda lo diferencial; esto no es considerado por Kant tema de la filosofía critica, pues entiende que sólo un idealismo absoluto tiene la pretensión de dar razón del dinamismo o carácter diferenciador. Ahora bien, 


\section{TOPICOS}

cabria objetar al planteamiento kantiano, entre no abordarlo, relegado al reino de la ilusión, y reducirlo al dinamismo generador de la razón cabe un término medio, a saber: que lo diferencial sea operativo en primera instancia, en la referencia del conocimiento a la realidad; $y$, por tanto, que sea el indicio irrefutable de la trascendencia del conocer y la razón no sea la instancia que regule lo diferenciado.

Si lo diferencial es operativo en primera instancia y no de un modo reflexivo, habría que decir, frente al planteamiento kantiano, que no existen verdaderas aporfas o conflictos en los que la razón humana no pueda aclararse (puede ocurrir que en un momento determinado no sepamos explicar, es decir, disolver tales aporias). La razón no puede plantearse algo que la supera de tal modo que no le sea posible, por 10 menos, indicar su identidad. Y es que la razón es en su origen principial ${ }^{27}$. Admitir al menos un primer principio o principio universal del conocer, supone que desde éste las aporias o conflictos son formulables en unos términos que permitan reconocer el ámbito en el que surge el enredo. Esta es la confianza que se respira en la Dialéctica. Toda filosofía tiene en su rafz un principio universal. Y, sin embargo, en la filosofía trascendental la gran aporía es el inexorable destino de una razón que, al mismo tiempo, reclama para sf la total transparencia e ilustración respecto a su acción (y no los conflictos dialécticos que señala Kant).

Antes aludía a los primeros principios del conocer; estos tienen la virtualidad de anular lo aporético, pero ellos no son lo diferencial, sino los que permiten el reconocimiento de éste. El criticismo, en cambio, a fuerza de no reconocer lo diferencial

${ }^{27}$ En el comienzo de toda teorra del conocimiento y de toda metafísica hay una formulación del primer principio o principios. Su universalidad le convierte en árbitro de la diferencia. Toda distinción, toda ampliación del saber remite en último lugar a él. Por tanto, todo conflicto aporético es una subversión del primer principio. 
termina negándolo: lo fenoménico y lo ideal son igualmente representaciones. La diferencia aparece siempre; en el pensamiento kantiano sólo puede aparecer como naturaleza histórica de la razón y apercepción trascendental. Pero, este es un ámbito supraprincipial en la filosoffa kantiana, y mantiene, por tanto, un carácter aporético ${ }^{28}$.

La Dialéctica, aunque sea el reino de la ilusión, es fértil y laboriosa. El uso dialéctico de la razón explica disciplinas de tanta raigambre en el ambiente filosófico como la cosmología racional, la teodicea o la psicología racional ${ }^{29}$. La Crítica no trata de contraponer sus concepciones sobre esas cuestiones a la tradición en la que inicia sus trabajos, ni de mejorar ésta para sacarla asf del callejón de los pleitos irresolubles en el que está metida. Las doctrinas que forman el cuerpo metafísico quedan refutadas por los principios a los que obedecen, por el alcance y

${ }^{28}$ En la filosofía contemporánea es muy frecuente identificar razón e historia y, por tanto, conocimiento e interpretación (desaparece uno de los elementos del conflicto). Lo real queda en cambio reducido a una materia indefinida, que es conformada por una razón que se descubre a si misma sólo como configuradora, diferenciadora $y$, en esa medida, es necesariamente intrahistórica. Razón e historia no son equiparables; en primer lugar, porque la historia depende de una inteligibilidad; consiguientemente no agota su principio. La historia no es lo mismo que la razón; la razón no es únicamente historia; es más, lo histórico -que es un modo del propio cognoscente- reclama, por su misma identidad, una diferencia, no respecto al ser como facticidad de los hechos, sino una diferencia dentro de lo racional (Kant lo llamarfa apercepción trascendental).

29 Kant no consideraba que alma, mundo y Dios fueran temas que aparecen s6lo en determinados sistemas filosoficos y en algunas visiones del mundo; justamente todo lo contrario, responden a inclinaciones necesarias radicadas en la naturaleza de la razón. Heimsoeth señala que estas tres inclinaciones se ordenan para Kant "como un alzarse desde el sujeto que se encuentra en el mundo, pasando sobre la totalidad del mundo hacia aquello más exterior y superior". Transzendentale Dialektik, I, p. 17. 


\section{TOPICOS}

validez de estos. Todo esto quiere decir que, aunque la metafísica no haya alcanzado un estatuto seguro en el marco de las ciencias, y pese a que la Analítica trascendental excluye del conocimiento objetivo todo lo que no sea fenómeno de experiencia, aquélla no tiene por qué desaparecer. Es fruto de las inevitables tendencias naturales de la facultad superior de conocer: la razón pura.

Kant no se ofusca en su fijación por lo empírico. A lo fenoménico como tal le bastan unas leyes que lo recojan en una estructura en la que queden prendidos sus modos de aparecer, de ser en los sentidos; su precariedad y variabilidad hace que sea más relevante conocer su causa eficiente que la interna conexión de las cualidades de un objeto, conexión que tendría que nacer de un principio o naturaleza en sí mismo.

Pero, ¿no es cierto que, de alguna manera, uno siente la tentación de dar la razón a Kant? En el marco de las cosas experimentadas todo tiene que ver con todo, sobre todo los sucesos y las cosas que forman parte de ese entorno que llamamos naturaleza (los actos humanos y sus objetivaciones culturales, de un modo aún más claro, no pueden ser considerados aislados de otros actos). Pretender que muchos de los elementos de lo que llamamos mundo tengan una entidad en si misma, que permita su conocimiento sin reclamar de inmediato su localización en un conjunto de relaciones causales, de interacciones, trae bastantes complicaciones (las que surgen, por ejemplo, cuando se intenta concretar determinadas categorizaciones de la metafísica en las cosas que nos rodean).

Kant piensa que para dominar la naturaleza, móvil y cambiante en sus manifestaciones, basta con esa estructuración de la realidad que da una cierta solidez a lo que empíricamente no la tiene. Eso sí, tal estructuración tiene que ser a priori, lo contrario serfa fijar lo móvil, error fácilmente comprobable porque éste seguiría siendo móvil. En las categorías kantianas 
encontramos una ontología de la experiencia que formula universalmente los dinamismos de la realidad empírica.

En relación con la postura kantiana expuesta anteriormente, merece la pena insistir en que, aunque la realidad -en tanto que objeto de la sensibilidad- sea manifestación, fenómeno, suscita las preguntas metafísicas: el cambio precisa de lo permanente; 10 manifestado no puede absorber todo el ser de lo que se manifiesta; el dinamismo del cambio o es eterno o es creado. Saber que el conocimiento de la realidad en su carácter sensible es apariencial, dice también algo del cognoscente: conocer no es ser y, sin embargo se conoce la realidad. Esa diferencia (la que significa apariencia) no conduce a la inmanencia -como se deriva del planteamiento kantiano-, sino todo lo contrario, a la trascendencia del conocimiento. Por ello, pueden ser objeto de nuestras investigaciones (frente a un pensamiento inmanentista como el trascendental) el mundo, Dios, el alma humana - sin ser aparienciales-, porque notar lo aparente implica no reducir lo real a lo fenoménico. Justamente la inteligencia reclama conocer lo real para conocer lo aparente.

La razón kantiana tampoco queda satisfecha con lo aparente, con lo fenoménico; pero, la inmanencia de sus principios hace que no sea lo fenoménico lo que, por no ser conocido suficientemente, tienda a la idea de totalidad. El inmanentismo kantiano descubre los principios constitutivos de lo aparente en la razón. Con ello la única diferencia que puede surgir es la de una razón que naturalmente reclama la totalidad de lo compuesto, de lo divisible, de lo movil; la unidad de los actos internos del sujeto; la existencia necesaria o la completa determinación de las cosas. Pero en ese caso la metafísica es solo un saber sobre la razón y sus principios y no un saber sobre la realidad. 
60

\section{TOPICOS}

La filosofía trascendental permite únicamente una metafísica entendida como dialéctica; una ciencia que no trata sobre el ser y sus modos, sino sobre la razón y sus intereses. 
Copyright of Tópicos. Revista de Filosofía is the property of Universidad Panamericana and its content may not be copied or emailed to multiple sites or posted to a listserv without the copyright holder's express written permission. However, users may print, download, or email articles for individual use. 